\title{
THE STUDIES AND COMPARATIVE EVALUATION OF THE FUNCTIONAL AND MATERIAL CUMULATION OF NANO AND MICRODISPERSED NICKEL OXIDE CONSUMED BY THE PERORAL ROUTE
}

\author{
M.A. Zemlyanova ${ }^{1}$, T.I. Akafeva ${ }^{1}$, A.A. Dovbysh ${ }^{1}$, S.A. Smirnov ${ }^{2}$ \\ ${ }^{1}$ FBSI "Federal Scientific Center for Medical and Preventive Health Risk Management Technologies", Russian \\ Federation, Perm, 82 Monastyrskaya St., 614045 \\ ${ }^{2}$ FSBEI HPE «Perm National Research Polytechnic University», Russian Federation, Perm, 29, Komsomolsky \\ Prospect St., 614990
}

The results of the research and comparative assessment of the cumulative properties of nanodisperse and microdisperse nickel oxide in the experiment are presented. It is found that after the intragastric gavage of the nanodisperse nickel oxide for 16 days (total dose administered was $16250 \mathrm{mg} / \mathrm{kg}$ ) it possesses a functional accumulation, as it is evidenced by the morphological changes in the tissues of the gastrointestinal tract, liver, spleen, and material accumulation indicator which is an increase of its concentration in the brain, liver and kidneys relative to controls (4.7, 8.1 and 23.6 times, respectively). Microdisperse analague also has a functional and material accumulation, but the degree of manifestation is different from the accumulation of nanodisperse nickel oxide. The accumulation of the substance occurs only in brain and liver, and in lower concentrations as compared to the nanodisperse nickel oxide (1.7 and 3.6 times). The morphological changes of tissues of the gastrointestinal tract and the spleen are less pronounced, any change in liver tissue is not established.

Key words: nanodisperse and microdisperse nickel oxide, peroral route, material accumulation, functional accumulation, morphological changes.

Introduction. Today's growing development and commercialization of the products that contain nanomaterials, as well as expansion of the market that uses nanotechnologies in the production of goods require special attention to the assessment of safety of nanomaterials for public health and the environment $[1,6,7]$. A marketing study of the global market in 2014 reported that the amount of manufactured nanodispersed metal oxide powders totaled 400000 tons, including $20 \%$ of nanodispensed nickel oxide [8]. Nanodispensed nickel oxide is widely used in electrical instrument-making, nano-optics, biodiagnostics (as chemical sensors), chemical and metallurgical industries, and is also used to create a variety of coatings, polymers, textiles [1]. The enterprises operating in those fields can pollute the water bodies with nickel oxide nanoparticles thus substantiating the possibility of oral intake with drinking water.

For this reason, the study of the toxicity parameters for nanodispersed nickel oxide with oral intake including its ability to cumulate in a human body is an issue of current interest. The present study is a part of a series of studies on hygienic assessment of the safety of materials which contain nanoparticles conducted by the Federal Research Center for Medical and Preventive Health Risk Management Technologies [3].

(C) Zemlyanova M.A., Akafeva T.I., Dovbysh A.A., Smirnov S.A., 2015

Zemlyanova Marina Aleksandrovna - M.D., Head of the Department biochemical and cytogenetic diagnostic methods (e-mail: zem@ fcrisk.ru; tel.: +7 (342) 236-39-30).

Akafeva Tatiana Igorevna - junior researcher of the Laboratory of biochemical and nanosensory diagnostics (e-mail: akafievat@fcrisk.ru; tel.: +7 (342) 236-39-30).

Dovbysh Anastasia Aleksandrovna - toxicologist of the Laboratory of metabolism and pharmacokinetics (e-mail: dovnastja@yandex.ru; tel.: +7 (342) 236-39-30).

Smirnov Sergey Aleksandrovich - junior researcher of the chair of chemical engineering (e-mail: po4tamoia@ mail.ru; tel.: +7 (342) 239-16-44). 
Materials and methods. To assess the cumulative effect, we used nanosized nickel oxide powder with the particles sized $<50 \mathrm{~nm}$ (SigmaAldrich, США) [7]. In the comparative study, we used microdispersed nickel oxide powder with the particles sized 10-50 $\mu \mathrm{m}$ (Sigma-Aldrich, США) [6]. Immediately before the start of the experimental studies, the tested substances were turned into aqueous suspension by adding the powder to distilled water that satisfied TU 6-09-2502-77. Then, to break the aggregates and agglomerates of the particles in the tested suspension of nanodispersed nickel oxide and for an even distribution of the particles, we performed ultrasonic treatment on ultrasonic homogenizer Sonopuls Hd 3200 (Bandelin, Germany) at room temperature for 2 minutes using the mode of continuous pulsation at $65 \%$ power. The concentration of the tested substance both in the nanodispersed nickel oxide suspension and microdispersed analogue suspension totaled 400 $\mathrm{mg} / \mathrm{cm}^{3}$.

The study of the cumulative effect of the nanodispersed nickel oxide in aqueous suspension as compared to a microdispersed analogue was conducted following the procedure described by R.K.S. Lim et al and MU 1.2.2869-11 [2, 5]. To determine the parameters of the cumulative effect of the tested suspensions, we set up a detailed experiment on white Wistar males weighing $290 \pm 10$ g. The rats were allocated to 3 groups: experimental group No 1, comparison No 2, and control No 3 (10 rats in each group). The tested aqueous suspensions of nano- and microdispersed nickel oxide were daily administered intragastrically to the rats from the groups No 1 and 2 respectively. The daily dose was calculated with the account for $\mathrm{LD}_{50}$ determined at the preliminary stage for nanodispersed nickel oxide and administered orally, totaling more than 5000 $\mathrm{mg} / \mathrm{kg}$ body mass. Nanodispersed nickel oxide in aqueous suspension was administered according to the following protocol: in the first 4 days, the dose was $500 \mathrm{mg} / \mathrm{kg}$ body mass per day $\left(1 / 10 \mathrm{LD}_{50}\right)$, every 4 days thereafter the dose was increased 1.5 times to reach the maximal possible single administered dose. The total dose of nanodispersed nickel oxide and, accordingly, microdispersed analogue administered throughout the entire experiment was $16250 \mathrm{mg} / \mathrm{kg}$ body mass. Variation of the doses of the tested substance was achieved by changing the volume of administered suspension (in ml of solution) without dilution. Microdispersed nickel oxide in aqueous suspension was administered in the similar doses. The rats in the control group a single dose of distilled water that satisfied TU 6-09-2502-77 daily, intragastrically, the same amount as the aqueous suspension. The experiment lasted 16 days. The functional cumulative effect was assessed by the number of dead rats and the appearance of morphological changes in the tissues of the visceral organs; the materials cumulative effect was assessed by amount of accumulated tested substances in the brain, kidney, and liver. The relationship between the morphological changes in the tissues and exposure to the tested substance was assessed by calculating the odds ratio and the confidence interval (OR, DI). The relationship was established at $\mathrm{OR}>1$ [4].

The concentration of the substance in the nanoand microdispersed nickel oxide suspensions was verified immediately before administration to the animals. During the experiment, we evaluated the lethal effect and changes in the body mass. The animals were removed from the experiment on the $16^{\text {th }}$ day with the help of carbon dioxide.

To study the morphological changes in the organ tissues, we selected the visceral organs (heart, lung, spleen, liver, kidney, stomach, pancreas, stomach, small intestine and colon) in 50\% of the animals from each of the groups using Shore's full evisceration method.

The brain and femur were removed for histological analysis. The collected material was then immediately fixed in $10 \%$ neutral buffered formalin solution. Dehydration of the fixed pieces of tissues was carried out in an automatic histological processor Excelsior ES (Thermo Scientific, Germany). Histological preparations were made from paraffin sections 3-4 microns thick, using hematoxylin and eosin staining in Varistain Gemini ES automated slide stainer (Thermo Scientific, Germany). The resulting slides were examined with the help of the light-optical microscope Axio Lab A1 (Carl Zeiss, Germany); microphotographs were made using Mikroskopkamera AxioCam ERc 5s camera (Carl Zeiss, Germany) at $200 \times, \times 400, \times 1000$ magnification. The morphological changes in the organs of experimental animals from the groups 1 and 2 were compared against the morphological structure of the tissues and organs of the control group 3 .

To assess the material cumulative effect of nickel, we selected the brain, kidney, and liver in $50 \%$ of the animals from each of the groups. Quantitation of nickel in the samples was performed with the help of inductively coupled plasma mass spectrometry on Agilent 7500cx (Agilent, USA) using a collision/reaction cell, and helium as a reaction gas. 
To transfer the samples into the tested solutions, the samples were thermally ignited for 9 hours in the muffle furnace at $450-500{ }^{\circ} \mathrm{C}$. The concentration of nickel was calculated with the account for the organ mass. The changes in the nickel concentrations in the analyzed organs of the experimental animals from the group 1 and 2 were assessed against the indicators in the control group 3 .

All the studies and procedures were performed in accordance with the rules adopted by the European Convention for the Protection of Vertebrate Animals Used for Experimental and Other Scientific Purposes
(Strasburg, 1986), and the Ethics Committee of the Federal Scientific Center for Medical and Preventive Health Risk Management Technologies.

Results. The study of the functional cumulative effect of nanodispersed nickel oxide showed that during the experiment, no deaths of the experimental animals in the experimental group No 1, comparison group No 2, and control group No 3 were registered. The body mass of the experimental animals from the groups 1 and 2 did not change significantly as compared to the control group (Table 1).

Table 1

The changes in the body mass of the experimental animals in the study of the cumulative effect of nanoand microdispersed nickel oxide

\begin{tabular}{|c|c|c|c|c|}
\hline \multirow{2}{*}{ Group } & \multicolumn{2}{|c|}{$\begin{array}{l}\text { Average body mass in a group, } g \\
(\mathrm{M} \pm \mathrm{m})\end{array}$} & \multirow{2}{*}{$\begin{array}{c}\text { Average weight gain in a } \\
\text { group as compared to the } \\
\text { baseline, } \%\end{array}$} & \multirow{2}{*}{$\begin{array}{l}\text { Difference in the body mass } \\
\text { between the groups against the } \\
\text { control group on the } 16^{\text {th }} \text { day of the } \\
\text { experiment }(p<0,05)\end{array}$} \\
\hline & $\begin{array}{l}\text { Before the } \\
\text { experiment }\end{array}$ & $16^{\text {th }}$ day & & \\
\hline Group № 1 & $275,9 \pm 14,8$ & $260,5 \pm 19,0$ & $-5,6$ & 0,098 \\
\hline Group № 2 & $289,9 \pm 18,2$ & $280,1 \pm 38,6$ & $-3,4$ & 0,876 \\
\hline $\begin{array}{l}\text { Group № } 3 \\
\text { (control) }\end{array}$ & $281,2 \pm 19,1$ & $282,5 \pm 15,3$ & $+0,2$ & - \\
\hline
\end{tabular}

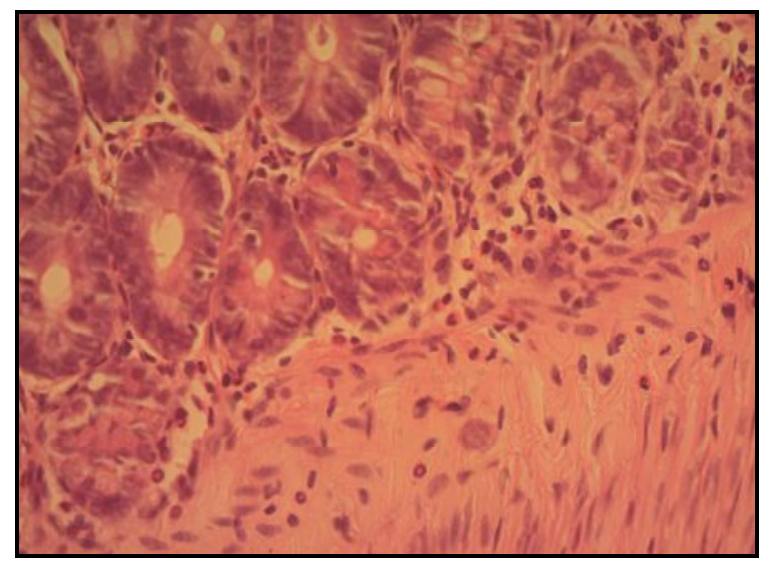

$a$

Rat ileum. Total dose of nanosized nickel oxide - 16250 $\mathrm{mg} / \mathrm{kg}$, h/e staining $x 200$

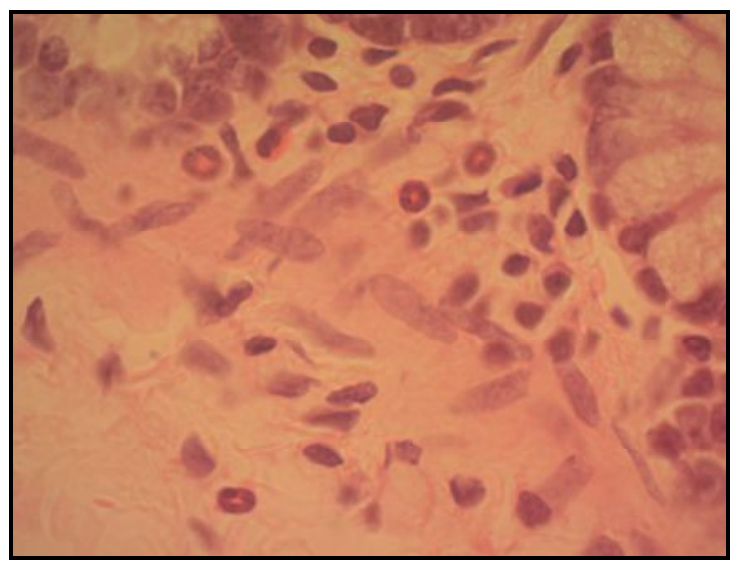

$a$

Rat colon. The total dose of nanosized nickel oxide $16250 \mathrm{mg} / \mathrm{kg}$, h/e staining, x1000 


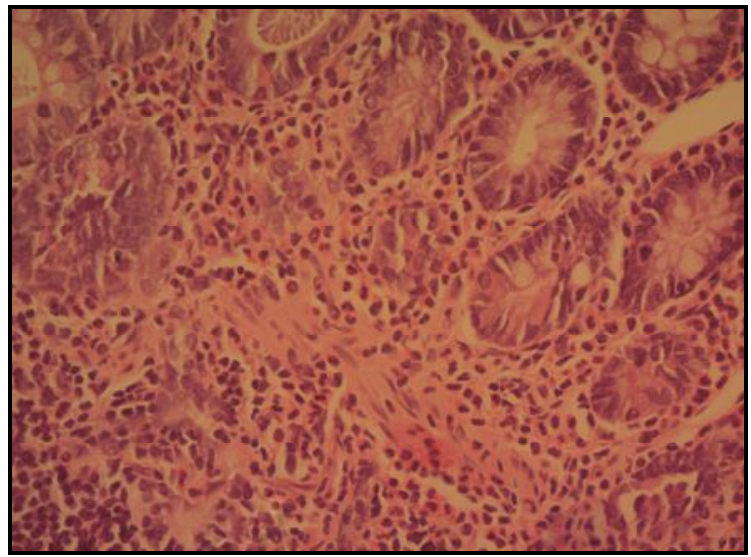

$\sigma$

Fig. 1 - Rat ileum. Total dose of microdispersed nickel oxide $-16250 \mathrm{mg} / \mathrm{kg}$, h/e staining x200

At the same time, we revealed morphological changes in the gastrointestinal tissues in the experimental group 1 including hyperplasia of the lymphoid tissue and forming of reactive follicles and eosinophilia reactive infiltration in the small intestine (Fig. 1), and eosinophil infiltration in the colon along with Paneth cell hyperplasia (Fig. 2). We established a connection between the morphological changes in the gastrointestinal tissues and exposure to the tested substance $(\mathrm{OR}=3,5, \mathrm{DI}=2,35-4,78)$.

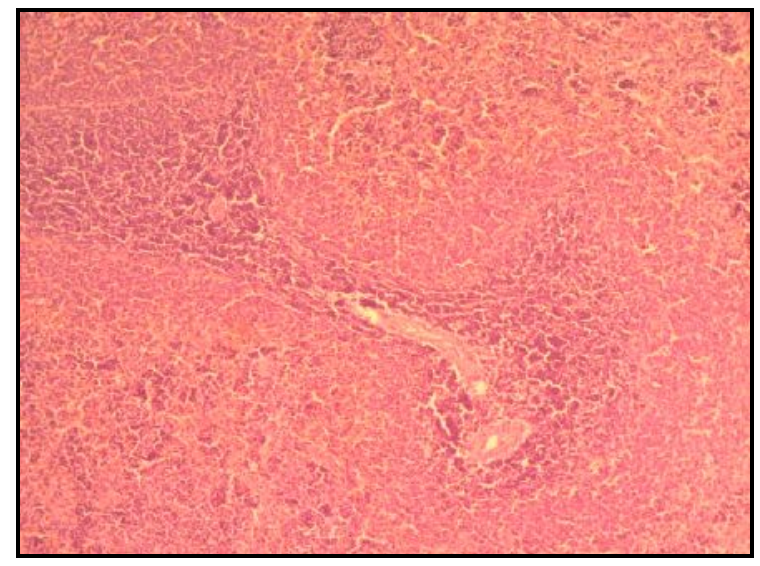

$a$

Rat spleen. Total dose of nanodispersed nickel oxide $16250 \mathrm{mg} / \mathrm{kg}$, h/e staining, x200

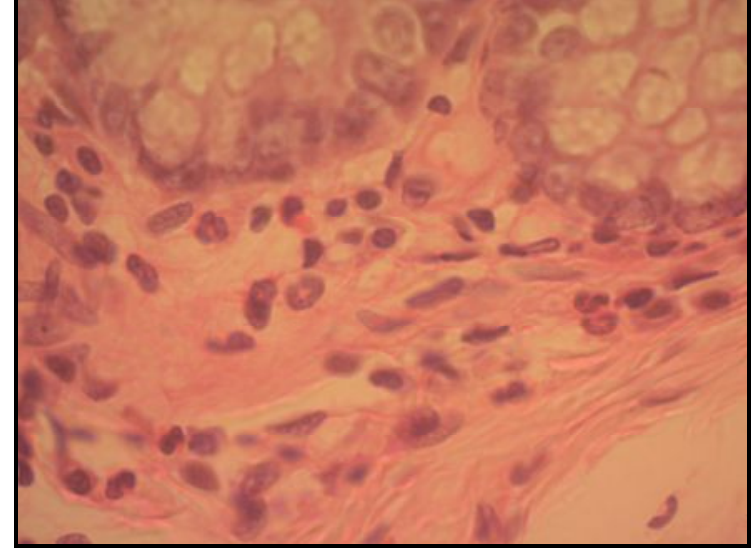

6

Fig. 2 - Rat colon. Total dose of microdispersed nickel oxide $16250 \mathrm{mg} / \mathrm{kg}$, h/e staining x1000

When analyzing the tissues of the experimental animals from group 2 who received aqueous suspension of the microdispersed analogue intragastrically, we registered similar morphological changes in the tissues of the small colon and colon as in group 1 (Figures 3,4); Paneth cell hyperplasia, however, was not found (Figure 4).

Connection between the morphological changes in the gastro and exposure to the tested substance $\quad(\mathrm{OR}=1,8, \quad \mathrm{DI}=1,25-2,95)$.

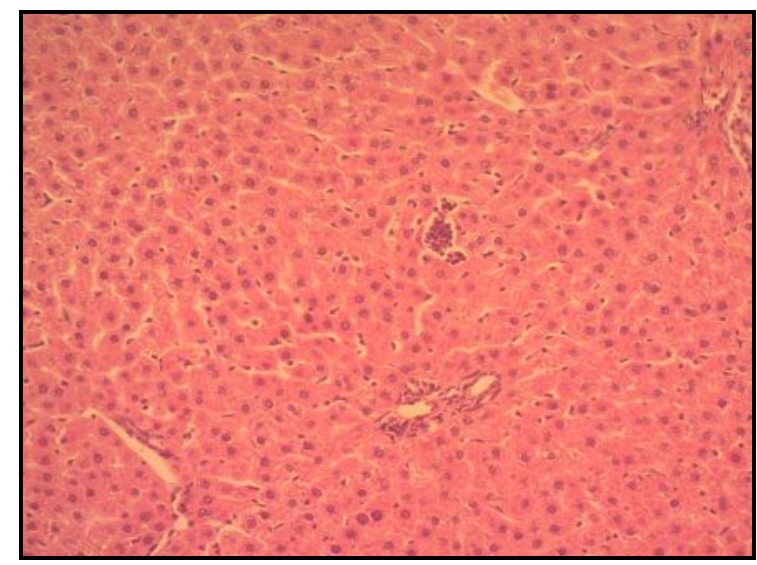

$a$

Rat liver. Total dose of nanodispersed nickel oxide $16250 \mathrm{mg} / \mathrm{kg}, \mathrm{h} / \mathrm{e}$ staining, $\mathrm{x} 200$ 


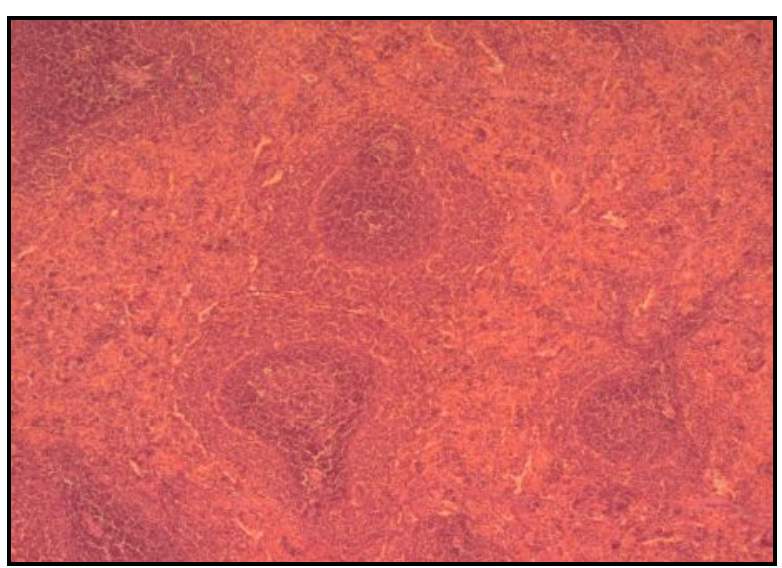

6

Fig. 3 - Rat spleen. Total dose of microdispersed nickel oxide - $16250 \mathrm{mg} / \mathrm{kg}$, g/e color, x200

We registered morphological changes in the parenchymal organs (spleen and liver) of the animals from group 1 manifested in lymphoid hyperplasia of the spleen tissue and an up to $45 \%$ increase in the volume of white pulp (Fig. 5), and the formation of reactive follicles and degeneration of the liver parenchymal protein, accompanied by infiltration with admixture of eosinophils in the portal tracts and gaps sine waves (Fig. 6). We established a connection between the revealed morphological changes in the spleen and liver and exposure to nanodispersed nickel oxide $(\mathrm{OR}=4,5$, $\mathrm{DI}=3,25-5,74)$.

A morphological examination of the parenchymal organ tissues of the animals from the comparison group 2 showed less pronounced changes in the spleen compared to the group 1; the changes included hyperplasia of the lymphoid tissue of the spleen with an up to $35 \%$ increase in the volume of white pulp, and eosinophilia of the marginal zones and red pulp (Fig. 7). Morphological changes in the liver tissue in this group were not found (Fig. 8). We established a connection between the morphological changes in the spleen with microdispersed nickel oxide exposure $(\mathrm{OR}=1,5, \mathrm{DI}=3,12-2,47)$.

The analysis of the tissues of the brain, heart, lungs, kidney, adrenal glands, and bone marrow of the animals from the groups 1 and 2 did not reveal any morphological changes as compared to the control group.

The analysis of the material cumulative effect showed that the animals from group 1 who had been receiving nanodispersed nickel oxide in aqueous suspension had a higher concentration of the tested substance in the brain, liver, and kidney

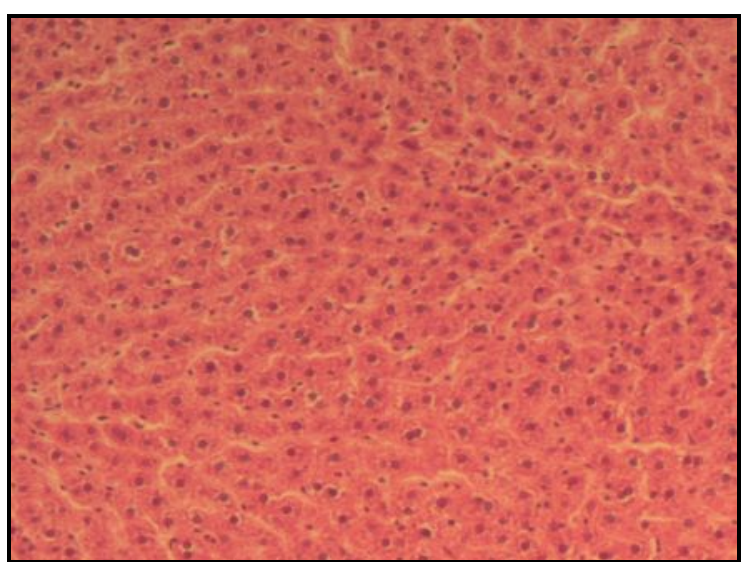

$\sigma$

Fig. 4 - Rat liver. Total dose of microdispersed nickel oxide - $16250 \mathrm{mg} / \mathrm{kg}$, g/e color, $\mathrm{x} 200$

as compared to the control group by 4,7, 8,1 and 23,6 times

The animals from group 2 who had been receiving microdispersed nickel oxide in the similar amount showed increased concentrations only in the brain and liver - by 2.8 and 2.2 times as compared to the control group. The comparison of the level of nickel in the organs of the animals from groups 1 and 2 established that the group that had been receiving nanodispersed nickel oxide had a higher concentration of the substance in the brain, liver, and kidney - by 1.7, 3.6 and 33.0 times as compared to the group that had been receiving a microdispersed analogue (Table 2).

We established that nanodispersed nickel oxide administered to the experimental animals from group 1 deposited mainly in kidney, unlike microdispersed analogue, and was also found in the brain and liver in large quantities. This effect can be explained by high adhesion of the nanoparticles to the surface which stimulates their penetration through the tissue barriers (gut epithelial barrier, the blood-brain barrier).

Conclusion. The performed study showed nano- and microdispersed nickel oxide in aqueous suspension demonstrates a functional cumulative effect when administered orally. Despite the fact of zero deaths among the experimental animals, exposure to nanodispersed nickel oxide causes pronounced morphological changes in the tissues of colon and small colon, spleen, and liver. Exposure to a microdispersed analogue caused less pronounced changes in the tissues of the colon and small colon, and spleen. 
Table 2

Results of the analysis of the material cumulative effect of nano- and microdispersed nickel oxide in aqueous suspension administered intragastrically

\begin{tabular}{|c|c|c|c|c|c|}
\hline \multirow{2}{*}{ Animal group } & \multirow{2}{*}{\multicolumn{2}{|c|}{ Indicators }} & \multicolumn{3}{|c|}{ Concentration of nickel oxide in the tissue, $\mathrm{mg} / \mathrm{kg}$} \\
\hline & & & Brain & Liver & Kidney \\
\hline Control group 3 & \multicolumn{2}{|c|}{ Mean value $(\mathrm{M} \pm \mathrm{m})$} & $0,0225 \pm 0,009$ & $0,104 \pm 0,01$ & $0,046 \pm 0,005$ \\
\hline \multirow{4}{*}{ group 2} & \multicolumn{2}{|c|}{ Mean value $(\mathrm{M} \pm \mathrm{m})$} & $0,062 \pm 0,015$ & $0,233 \pm 0,02$ & $0,033 \pm 0,008$ \\
\hline & \multicolumn{2}{|c|}{$\begin{array}{l}\text { Difference between the groups as compared to the } \\
\text { control }(\mathrm{p}<0,05)\end{array}$} & 0,026 & 0,001 & 0,026 \\
\hline & \multirow{2}{*}{$\begin{array}{l}\text { Multiplicity of differences } \\
\text { with the control }\end{array}$} & Higher than the control & 2,76 & 2,24 & - \\
\hline & & Lower than the control & - & - & 1,39 \\
\hline \multirow{5}{*}{ group 1} & \multicolumn{2}{|c|}{ Mean value $(\mathrm{M} \pm \mathrm{m})$} & $0,1063 \pm 0,019$ & $0,843 \pm 0,10$ & $1,09 \pm 0,13$ \\
\hline & \multicolumn{2}{|c|}{$\begin{array}{l}\text { Difference between the groups as compared to the } \\
\text { control }(\mathrm{p}<0,05)\end{array}$} & 0,001 & 0,001 & 0,001 \\
\hline & \multicolumn{2}{|c|}{ Multiplicity of excess of the control } & 4,7 & 8,1 & 23,6 \\
\hline & \multicolumn{2}{|c|}{ Intergrouppal difference with group $2(\mathrm{p}<0,05)$} & 0,030 & 0,003 & 0,001 \\
\hline & \multicolumn{2}{|c|}{ Multiplicity of excess indicators of group 2} & 1,7 & 3,62 & 33,03 \\
\hline
\end{tabular}

We established the presence of a material cumulative effect for both of the tested substances. However after administration of microdispersed nickel oxide, the concentration of nanodispersed nickel oxide in the tissues of the brain, liver, and kidney grew by 1.7, 3.6, and 33.0 times as compared to the similar indicators. Moreover, we observed pronounced morphological changes in the tissues of the small (ileum) colon and colon in the form of lymphoid tissue hypertension accompanied by reactive follicular hyperplasia of spleen lymphoid tissue with an up to $45 \%$ increase in the white pulp volume, and liver in the form of a parenchymal protein dystrophy. A morphological analysis of the tissues that the changes are less pronounced in the gastro and spleen; no changes in the liver tissues were observed.

In view of the above, nickel oxide nanoparticles have a high potential to overcome internal and external body barriers (barrier of the gastrointestinal tract and the blood-brain barrier) as compared with a microsized analogue. Long-term exposure can cause morphofunctional disorders in the tissues of the gastrointestinal tract, parenchymal organs, and brain. Slow elimination and the lack of pronounced toxic effect of both nano- and microdispersed nickel oxide can be explained by a high level of coupling with the blood plasma protein.

To conclude, the results of the performed studies and comparative assessment of the cumulative effect of nano- and microdispersed nickel oxide administered intragastrically in the total amount of $16250 \mathrm{mg} / \mathrm{kg}$ showed that the tested substances demonstrate a functional and material cumulative effect. For nanodispersed nickel oxide, the effect is more pronounced. The fact of the functional cumulative effect in nanodispersed nickel oxide can be confirmed by the presence and degree of manifestation of the morphological changes in the tissues of small colon, colon, liver, and spleen; in the case of microdispersed nickel oxide, the morphological changes in the tissues of the small colon and colon, and spleen are less pronounced; the changes in the liver tissues are not established. In the case of nanodispersed nickel oxide, the fact of material cumulative effect can be confirmed by its increase in the brain, liver, and kidney by 4.7 , 8.1, and 23.6 times as compared to the control group, in the case of microdispersed nickel oxide - the concentration increases only in the brain and liver, and it is by 1.7 and 3.6 times lower as compared to the concentrations in these organs in the exposure to nanodispersed nickel oxide. For a more detailed assessment of the nature of the effect that nano- and microdispersed nickel oxide have on the body under repeated exposure, it is necessary to study the negative effects and toxicity of the tested substances in the setting of chronic exposure. 


\section{References}

1. Aleshina I.V., Aleshin Je.B. Globalizacija rynkov, nanoindustrija i strategija internet-prodvizhenija nanoproduktov RF [Globalization of markets, nanotech industry and Internet promotion strategy of nanoproducts in Russian Federation]. Marketing v Rossii i za rubezhom, 2010, no. 3, pp. 104-116. (in Russian).

2. Gigiena, toksikologija, sanitarija. Porjadok ocenki toksicheskogo dejstvija nanomaterialov na laboratornyh zhivotnyh MU 1.2.2869-11 [Hygiene, toxicology, sanitation. The procedure of evaluation of the nanomaterials' toxic effect to the laboratory animals RP 1.2.2869-11]. Federal'naja sluzhba po nadzoru v sfere zashhity prav potrebitelej i blagopoluchija cheloveka, 2011, 25 p. (in Russian).

3. Zaitseva N.V., Zemlyanova M.A., Zvezdin V.N., Saenko E. V. Toksikologo-gigienicheskaja ocenka bezopasnosti vodnoj suspenzii nanodispersnogo dioksida kremnija, sintezirovannogo metodom zhidkokristallicheskogo templatirovanija [Toxicological-hygienic assessment of aqueous suspension's security of the nanodisperse silica dioxide, synthesized by a liquid crystal self-assembly]. Analiz riska zdorov'ju, 2013, no. 1, pp. 65-72. (in Russian).

4. Fletcher R., Fletcher S., Vagner Je. Klinicheskaja jepidemiologija. Osnovy dokazatel'noj mediciny [Clinical epidemiology. Basics of evidence based medicine]. Moscow: Media Sfera, 1998, 352 p. (in Russian).

5. Lim R.K. [et al.]. A method for the evaluation of cumulation and tolerance by the determination of acute and subchronic median effective doses. Arch. Int. Pharmacodyn. Ther, 1961, no. 130, pp. 336-353.

6. Nickel (II) oxide powder, $99.8 \%$ trace metals: material safety data sheet (MSDS). Sigma-Aldrich, 2014,7 p.

7. Nickel (II) oxide nanopowder, $<50 \mathrm{~nm}$ particle size (TEM), $99.8 \%$ trace metals: material safety data sheet (MSDS). Sigma-Aldrich, 2014, 8 p.

8. The Global Market for Metal and Metal Oxide Nanoparticles to 2025. Market Reports Online, 2015. Available at: http: //www.marketreportsonline.com/401808-toc.html (09.10.2015). 